REVISTA ELECTRÓNICA DE RECURSOS EN INTERNET SOBRE GEOGRAFÍA Y CIENCIAS SOCIALES

Universidad de Barcelona

ISSN I578-0007

Vol. XXV. Núm. 257

I de agosto de 202I

DOI: https://doi.org/ I0.1344/ara202 I.257.35695

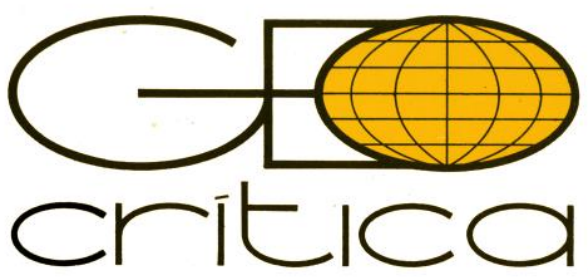

\title{
¿Telarañas digitales e hiperrealidad? Cavilaciones sobre ciberespacios, proto-cíborgs y realidades aumentadas en espacios públicos
}

\author{
Jeffer Chaparro Mendivelso \\ Departamento de Geografía, Universidad Nacional de Colombia \\ jchaparro@unal.edu.co
}

\begin{abstract}
¿Telarañas digitales e hiperrealidad? Cavilaciones sobre ciberespacios, proto-cíborgs y realidades aumentadas en espacios públicos (Resumen)
\end{abstract}

Los avances recientes en las tecnologías digitales son bastante potentes. Entre ellos se encuentra la realidad aumentada (RA), que involucra una gran cantidad de dispositivos de alta tecnología para su funcionamiento. Es así que se están estableciendo telarañas digitales muy fornidas y poderosas. Este artículo está dividido en siete segmentos. El primero es una apertura a la investigación. El segundo aborda el asunto de los ciberespacios y sus consecuencias para considerar el surgimiento de los metaversos. El tercero gira en torno a los proto-cíborgs como expresión de la imbricación profunda de las tecnologías digitales en la especie humana. El cuarto versa directamente sobre la RA y sus diversas implicaciones espaciales. La quinta parte apunta a discutir las consecuencias de estas tecnologías digitales de vanguardia en los espacios públicos. La sexta sección reflexiona sobre los vínculos de la RA con el cine de ciencia ficción. El último apartado, a modo de cierre conclusivo, discute la hiperrealidad como fenómeno espacio-temporal ontológico y emergente.

Palabras clave: Ciberespacio; Cíborg; Realidad Aumentada; Ciencia ficción; Hiperrealidad.

Digital spiderwebs and hyperreality? Reflections on cyberspaces, proto-cyborgs and augmented realities in public spaces (Abstract)

Recent advances in digital technologies are quite powerful. Among them is augmented reality (AR), which involves a large number of high-tech devices for its operation. Thus, very chunky digital spiderwebs are being established. The article is divided into seven segments. The first is an openness to investigation. The second addresses the issue of cyberspaces and its consequences to consider the emergence of metaverses. The third revolves around proto-cyborgs as an expression of the deep imbrication of digital technologies in the human species. The fourth deals directly with AR and its various spatial implications. The fifth part to discuss the consequences of these cutting-edge digital technologies in public spaces. The sixth section reflects on the links between AR and science fiction cinema. The last section, by way of conclusive closure, discusses hyperreality as an ontological and emergent space-time phenomenon.

Keywords: Cyberspace; Cyborg; Augmented reality; Science fiction; Hyperreality. 
A la memoria de mi amigo Julio Guadarrama, quien concordaría conmigo en que somos hologramas...

\section{¿Por qué telarañas digitales?}

Las telarañas son creaciones fascinantes. Desde distintos campos del pensamiento les han otorgado un papel relevante en discusiones profundas. En la biología se consideran como redes de seda proteica que permiten a las arañas atrapar presas. Aunque poseen también otras funciones: avisar sobre movimientos en el entorno, proteger los huevos o hacer nidos. Las telarañas forman estructuras diversas, complejas y resistentes; en ocasiones son verticales, en otras horizontales, pueden integrar espirales y también embudos, se expresan en dos dimensiones, incluso en tres a modo de maraña. Desde el punto de vista de la depredación, las telarañas ahorran mucha energía al momento de atrapar una presa, pues, en general, la lucha entre la captura y la estructura es saldada a favor de la segunda; las ondas transmitidas por la telaraña avisan sobre lo ocurrido, le permiten al arácnido calcular algunas variables de la presa, como el peso y la forma, incluso se advierte que las señales pueden permitir detectar el tipo específico de captura. Las telarañas son redes muy finas y resistentes, poco visibles, que atrapan presas de tamaño y formas específicas. Las telarañas ofrecen información estratégica y son arquitecturas diseñadas para la captura ${ }^{1}$.

Las tecnologías digitales (TD), y en especial el ciberespacio, funcionan de manera muy semejante a las telarañas. Atrapan a las personas en redes de bites que parecen inofensivas, pero que pueden capturar la vida, incluso hasta exprimirla, de forma parcial o completa. Por estos días las telarañas digitales se extienden a manera de redes de telecomunicación y ondas electromagnéticas que invaden casi todo el planeta Tierra ${ }^{2}$, con efectos diversos, no siempre benéficos ${ }^{3}$. Sus precursoras fueron la radio y la televisión, aunque un poco antes se anticiparon los telégrafos y los teléfonos. Las telarañas digitales están en las primeras fases de evolución, pero ya son muy potentes y su difusión se amplifica a ritmos bastante acelerados ${ }^{4}$. Las telarañas digitales ofrecen información detallada y al milímetro de sus presas potenciales ${ }^{5}$.

La expansión espacial de las telarañas digitales es inédita en el devenir humano. En pocas décadas ha logrado lo inimaginable para muchos autores de ciencia ficción: espiar al milímetro y catalizar los comportamientos humanos, es decir controlar ${ }^{6}$. Es por ello que las formas de vigilancia e injerencia llegan hasta los espacios públicos. Aquí se halla mi motivación central: establecer los

\footnotetext{
${ }^{1}$ Foelix, 2011; Herberstein, 2011; Viera y Gonzaga, 2017.

${ }^{2} \mathrm{El}$ mar con los cables submarinos, el suelo con las redes de fibra óptica, el aire con las señales Wi-Fi.

${ }^{3}$ Sobre los efectos en la salud asociados a la expansión de las redes digitales inalámbricas sugiero consultar: Nehru, 2016; Singer, 2014.

${ }^{4}$ Chaparro, 2017.

${ }^{5}$ Sobre los problemas del espionaje, la intimidad, la manipulación y la mentira en la actual era digital sugiero consultar: Assange, 2012; Coleman, 2016; Domscheit, 2011; Herrera, 2012; Luján, 2015; Pirés, 2008 y 2014; Santana, Chaparro, Bonastra y Capel, 2014 <http://www.ub.edu/geocrit/aracne/aracne-179.htm>.

${ }^{6}$ Una de las primeras obras cinematográficas de ficción científica en proponer este asunto es THX 1138. Lucas, 1971. El tráiler puede verse aquí: 〈https://www.youtube.com/watch?v=eHgqfVQWv7s〉.
} 
¿Telarañas digitales e hiperrealidad? Cavilaciones sobre ciberespacios, proto-cíborgs y...

vínculos entre los ciberespacios y los espacios públicos, en el contexto temporal de fines de la segunda e inicios de la tercera década del tercer milenio ${ }^{7}$.

Para dar cuenta de las telarañas digitales he dividido el texto en seis secciones -en realidad son siete al sumar la presente introducción-. En la primera, centro la reflexión en torno a los ciberespacios, como elemento básico para comprender la transformación del régimen espacio-temporal del mundo a distintas escalas. En la siguiente, abordo el fenómeno del proto-cíborg, como propuesta para poder contextualizar muchas acciones y posturas humanas mediadas por las tecnologías digitales. La tercera componente la dedico a exhibir los rasgos principales de la Realidad Aumentada (RA), asumida como conjunto de retroacciones entre humanos y máquinas, que hasta ahora despega y con seguridad tendrá impactos considerables en las formas de relacionarse con el espacio, incluyendo por supuesto los espacios públicos. La cuarta parte gira alrededor de la discusión en cuanto a la hiper-privatización de los espacios públicos a raíz de la extensión de las telarañas digitales. La quinta ofrece reflexiones de la RA desde el conocimiento y el hiperconsumo a partir de la ciencia ficción. La última pretende proponer, a partir de conclusiones e ideas finales, discusiones alrededor de las implicaciones futuras asociadas al auge y expansión de las telarañas digitales.

La RA enmarca múltiples biseles de análisis, como cualquier asunto ligado al uso y difusión de la alta tecnología de uso civil, de tal manera que no solo posee segmentos de carácter utópico o distópico $^{8}$. La situación de uso del juego Pokémon $G O$ en muchas ciudades del mundo, y en el contexto territorial de la Universidad Nacional de Colombia sede Bogotá, denota, como en la leyenda de El Flautista de Hamelín, que se siguen sin reflexión las directrices de las telarañas digitales. En un sentido inverso la RA podría ofrecer posibilidades y potencialidades, tal vez inimaginables, para los campos del conocimiento a los que les interesa el espacio, incluyendo los espacios públicos.

\section{Caminos hacia los ciberespacios: ¿cuerdas, membranas, hologramas y metaversos?}

El ciberespacio es un concepto aún reciente ${ }^{9}$. No surgió en el ámbito académico, sino en la ciencia ficción, específicamente en la novela Neuromancer escrita por William Gibson ${ }^{10}$. En el ámbito de la geografía una de las primeras definiciones originales señala que el concepto se refiere a la intersección entre el espacio y las redes digitales, de tal manera que se genera un espacio híbrido o espacio digital ${ }^{11}$. En el momento de la conceptualización anterior desde la geografía aún no se habían vislumbrado las potencialidades de las redes inalámbricas y de la telefonía celular o móvil, por lo que las definiciones aún estaban ancladas, en esencia, a los computadores y a Internet ${ }^{12}$. En la

\footnotetext{
${ }^{7}$ Deseo agradecer de forma amplia la invitación de la profesora Carla Narciso para escribir este texto. Ha sido muy estimulante para mí cavilar sobre la relación entre el espacio público y las tecnologías digitales, situación que derivó en la redacción del presente documento.

${ }^{8}$ En cuanto a las utopías y las distopías, en relación con las tecnologías digitales, recomiendo ver: Chaparro, Velandia y Giraldo, 2016 <http://www.ub.edu/geocrit/xiv-coloquio/ChaparroVelandiaGiraldo.pdf>; Chaparro, Ávila y Giraldo, $2018<$ http://www.ub.edu/geocrit/XV-Coloquio/ChaparroAvila.pdf>.

${ }^{9}$ Chaparro, 2017.

${ }^{10}$ Gibson, 1984.

${ }^{11}$ Batty, 1997.

${ }^{12}$ López, 2006.
} 
actualidad es necesario incorporar la convergencia tecnológica, a partir del bit, que es una nueva unidad de medida de la realidad ${ }^{13}$, y que de manera consecuente remite a considerar que no existe un único ciberespacio sino varios, formados por segmentos de articulaciones digitales diferenciales multi-escalares sincrónicas y asincrónicas, que generan retículas, redes, de apariencia invisible, que conectan a personas con personas, lugares con lugares, máquinas con máquinas, y todas las opciones relacionales posibles.

El ciberespacio se erige como un concepto muy importante para aproximarse al espacio público en la actualidad, pues allí convergen: las redes digitales, expresadas en las señales electromagnéticas ondas-, que favorecen el funcionamiento de teléfonos celulares, teléfonos inteligentes, tabletas y demás dispositivos digitales disponibles -objetos técnicos-, utilizando distintas opciones de infraestructura -energía eléctrica, cables de fibra óptica, antenas-, junto a las personas que animan, viven y deambulan por la calle y otros lugares de acceso en teoría no restringido - espacio público-.

A partir de una perspectiva complementaria, incluso en el caso de los parques urbanos en los que se ofrece servicio de Internet gratuito, en realidad el nivel de privatización asociado al auge de los objetos técnicos digitales es tan amplio, a escala casi planetaria, que podría decir, sin temor a equivocarme y sin rubor, que estos lugares públicos son privatizados mediante las tecnologías digitales y el mismo ciberespacio. Como evidencio más adelante, el caso de la RA puede sentar las bases de una privatización aún mayor de los espacios públicos, incluso de los espacios más íntimos de las personas.

Las tecnologías digitales y el ciberespacio contienen otras acepciones muy relevantes que no deben ser olvidadas. Entre ellas deseo destacar el asunto del ciberespacio como expresión del diseño virtual, como representación espacial, ya sea del mundo real o de territorios imaginados. Esto nos remite de forma consecuente a un punto ontológico de la geografía: la cartografía, la representación del espacio y el auge digital en el diseño espacial ${ }^{14}$. No cabe duda reconocer que en la actualidad estamos viviendo un florecimiento de la espacialidad virtual a partir del uso de distintos objetos técnicos digitales ${ }^{15}$, de los cuales por ahora el teléfono inteligente es el hegemónico; planteo "por ahora", pues con la vertiginosa aceleración en la producción y masificación de objetos de alta tecnología de consumo semi-masivo, vale la pena no asumir posturas estáticas y conservadoras, ya que es muy probable que pronto otros tipo de dispositivos, híbridos o nuevos, entren en la escena del deseo y uso por parte de la población ${ }^{16}$. Uno de esos objetos digitales de gran potencialidad se asocia a los visores, gafas o cascos de realidad virtual, lo cual hace más cercana la apuesta que se está haciendo frente a la Realidad Virtual (RV) y la Realidad Aumentada (RA). El concepto de metaverso $^{17}$ cada vez es más real y tangible.

En cuanto a la RV vale la pena señalar que sus avances son considerables en la actualidad, a tal punto que hoy en día es posible desplazarse, viajar y perderse por mundos enteros simulados en el ciberespacio $^{18}$. Ello explica su auge tan fuerte, en especial en personas de temprana edad, al igual que en adolescentes y adultos jóvenes, quienes consumen contenidos digitales disímiles -deporte,

\footnotetext{
${ }^{13}$ Chaparro, 2017, p. 13-35.

${ }^{14}$ Fisher y Unwin (Eds.), 2002.

${ }^{15}$ Sobre la noción de objeto técnico recomiendo consultar: Santos, 2000.

${ }^{16}$ Respecto al consumismo de las sociedades contemporáneas, incluyendo el digital, sugiero indagar en: Bauman, 2009.

${ }^{17}$ Lombardi y Lombardi, 2010, p. 111-122.

${ }^{18}$ Este es el caso de Active Worlds, entre otros <https://www.activeworlds.com/>.
} 
¿Telarañas digitales e hiperrealidad? Cavilaciones sobre ciberespacios, proto-cíborgs y...

guerra, estrategia, diseño urbano- con niveles de facturación industrial muy elevados, que incluso son muy similares a los del cine de industria ${ }^{19}$. No cabe duda que parte de las adicciones digitales actuales se refieren a las distintas posibilidades de la RV disponibles en línea; aunque en la mayoría de los casos la interfaz siga siendo la pantalla, poco a poco se abre paso el uso de los periféricos especializados con visión estereoscópica.

A esta altura queda claro que, por muchas razones, tanto tecnológicas como de apropiación social y de representación espacial, no es posible señalar que existe un único ciberespacio, sino varios, diversos, y tal vez a futuro infinitos... Por ello al referirse al ciberespacio es mejor hacerlo en plural: ciberespacios. Si pensamos hacia adelante en el tiempo en otros protocolos de comunicación digital para Internet, en el uso de distintos segmentos de longitudes de onda del espectro electromagnético, e incluso en aparatos digitales nuevos que no existen hoy día, las posibilidades para los ciberespacios son bastante amplias. La noción de metaversos toma cada vez más fuerza y paralelamente nos aproxima a los multiversos de la física de punta ${ }^{20}$. El ciberespacio remite, ineludiblemente, a la teoría de cuerdas y membranas, a los hologramas ${ }^{21} \ldots$

Sin pretender abarcar la totalidad de las reflexiones, pese a todo lo anterior, no hay que olvidar que el ciberespacio requiere para su funcionamiento del espacio factual, del espacio material, de la infraestructura tecnológica y de la energía eléctrica. Tampoco conviene olvidar que la Tierra no es plana, así que la difusión, el uso y la apropiación de las tecnologías digitales, básicas para la existencia de los ciberespacios, tienen fuertes características ligadas a la diferenciación, específicamente respecto $\mathrm{a}^{22}: 1$ ) deseo de acceso o consumo de la técnica, 2) acceso real material, 3) uso de la técnica, 4) uso creativo e innovador, aspectos que además son mediados por los discursos centrales - público, privado y hacker ${ }^{23}$.

\section{Proto-cíborgs}

Los humanos somos producto de la técnica ${ }^{24}$. Al realizar en la actualidad un análisis profundo de la condición humana, no es extraño reconocer el nivel de artificialidad al que hemos llegado en los albores del tercer milenio: implantes para oír mejor, cirugías de ojos asistidas por robots de precisión, automóviles ensamblados en gran proporción por máquinas especializadas, marcapasos para asistir al corazón, aparatos que realizan tomas radiológicas del cuerpo humano, sistemas de sonido portátiles de alta fidelidad, entre muchos otros artefactos, todos ligados a los avances en las $\mathrm{TD}^{25}$.

El grado de artificialidad es bastante fuerte e incluye distintas TD en interacción con los humanos, tanto en términos del cuerpo como del cerebro ${ }^{26}$. Un teléfono celular es un aparato de comunicación

\footnotetext{
${ }^{19}$ El País, 2018, 5 de octubre

<https://cincodias.elpais.com/cincodias/2018/10/05/companias/1538763165_030915.html>.

${ }^{20}$ Kisak (Ed.), 2015; Greene, 2011.

${ }^{21}$ Herrera, 2014.

${ }^{22}$ El conjunto anterior define la segregación digital territorial. Chaparro, 2017, p. 37-90.

${ }^{23}$ Respecto a la perspectiva hacker sugiero remitirse a: Coleman, 2016; Domscheit, 2016; Wark, 2015.

${ }^{24}$ Agilar, 2009.

${ }^{25}$ Caronia, 2015.

${ }^{26}$ Grebowicz y Merrick, 2013.
} 
muy refinado, que usa el espectro electromagnético, y es una memoria exosomática a la vez ${ }^{27}$. Un videojuego en línea define un espacio virtual interactuando con el cerebro humano y sus emociones, sueños, anhelos y frustraciones. Conducir un vehículo nos aproxima a las primeras fases de uso de exoesqueletos muy potentes, en este caso para asistir al desplazamiento humano en las ciudades y entre asentamientos de distinto tamaño ${ }^{28}$. Analizar y discutir con profundidad estos asuntos permite establecer que, sin duda, estamos ingresando paulatinamente a otro estadio de la humanidad: el cíborg o el híbrido hombre-máquina, donde las TD son protagonistas, tanto desde el punto de vista factual como simbólico ${ }^{29}$.

Este no es un asunto que vincule solo nuestra relación con las TD y las máquinas. ¿Qué decir de algún personaje que transa en una bolsa de valores y compra, mediante la visualización de una imagen de satélite, miles de hectáreas de selva de tajo y decide arrasarla para introducir agroindustria, con especies vegetales modificadas genéticamente en algún laboratorio, sin importarle para nada los aborígenes que han vivido allí por milenios y la biodiversidad asociada a millones de años de ajuste de los sistemas naturales? Quien tome una decisión de este tipo es un cíborg, uno con gran poder de transformación espacial y de aniquilación de la vida ${ }^{30}$. Evidentemente también hay sujetos, cíborgs, que toman decisiones militares y bélicas que pueden involucrar el exterminio, la sangre y el dolor profundo de miles o millones de personas. La categoría cíborg es sinónimo de poder amplio y contextual ${ }^{31}$.

Pese a la gran potencia que están ostentando algunos humanos asistidos por las TD, en realidad al pensar en los cambios de las sociedades a escalas temporales más dilatadas, por ejemplo desde el paleolítico y el neolítico, incluso solo a partir de la finalización de la última gran glaciación, sería más adecuado y prudente referirse a proto-cíborgs, es decir, los primeros modelos de híbridos hombre-máquina asistidos por TD que ostentan gran poder, pero que aún no ha llegado a la cúspide de los posible y lo imaginable. ¡El conocimiento genera quimeras! ${ }^{32}$

Las tecnologías digitales han redefinido a los humanos. En estos tiempos una gran proporción de individuos usamos, sin reflexionarlo e interiorizarlo, memorias exosomáticas y terminales de comunicación de alcance global y extra-planetario, como en el caso de apreciar una imagen proveniente de alguno de los robots que se están explorando la superficie de Marte o de los telescopios que orbitan el planeta y que ofrecen paisajes del Universo profundo ${ }^{33}$. Evidentemente, de manera diferencial, somos seres hiper-tecnológicos.

\footnotetext{
${ }^{27}$ Chaparro, 2017, p. 256-260.

${ }^{28}$ Sobre los avances recientes en exoesqueletos véase: Yang, Gu, Zhang y Gui, 2017.

${ }^{29}$ Clark, 2004; Haraway, 1995; véase también: Jasso, 2008.

${ }^{30}$ Esta situación es completamente verificable para el caso de la cuenca del río Amazonas en América del Sur.

${ }^{31}$ Lo ocurrido en Oriente Próximo durante las dos últimas décadas es una clara muestra de ello. En cuanto a la relación cíborg-dron recomiendo ver la película Good Kill, basada en hechos reales. Niccol, 2014. Tráiler disponible en: <https://www.youtube.com/watch?v=pcDB6OZgqzo>. Para profundizar en el asunto de los drones y su poder letal véase: Arteaga, 2016; Berguen y Tiedemann, 2011; Etzioni, 2010; Gregory, 2011 y 2012; Hashim y Gregoire, 2012; Hasian, 2016; Kreps y Zenko, 2014; Luján, 2015; Marcus, Aiyer y Dombrowski, 2012; Pollack, 2018; Shaw, 2013; Chaparro, Coronado, García, Rabia y Zárate, 2018 <https://revistes.ub.edu/index.php/aracne/article/view/28463>; Chaparro, Velandia y Giraldo, 2016 <http://www.ub.edu/geocrit/xiv-coloquio/ChaparroVelandiaGiraldo.pdf>.

${ }^{32}$ Algunas pistas respecto al futuro humano que se está diseñando se encuentran en: Harari, 2016.

${ }^{33}$ No sobra dar un paseo por el sitio web de la NASA <https://www.nasa.gov/>.
} 
¿Telarañas digitales e hiperrealidad? Cavilaciones sobre ciberespacios, proto-cíborgs y...

El asunto proto-cíborg invita a establecer reflexiones muy recónditas e intrincadas respecto a la naturaleza artificial de lo humano, pero también a reconsiderar y amplificar las apuestas teóricas respecto a las geografías del cuerpo ${ }^{34}$. en las que se asume, con gran potencia y claridad, que el cuerpo debe considerarse como el primer territorio ${ }^{35}$. Para el proto-cíborg el cuerpo, como territorio inicial, se amplifica de manera sustancial e inédita, tal vez impensable hace apenas pocos años. Las telarañas digitales son extensiones y a la vez proyecciones de los proto-cíborgs en los espacios, incluyendo los públicos.

\section{Realidades Aumentadas}

¿Qué es la Realidad Aumentada (RA)? La RA puede considerarse como un conjunto de tecnologías digitales derivadas de la Realidad Virtual (RV), en las cuales se combina el espacio factual real con el espacio virtual, es decir vincula espacio y ciberespacio en tiempo real. La RA inserta objetos virtuales en el espacio efectivo cotidiano mediante la potencia de Internet, el geoposicionamiento, los dispositivos móviles y la Inteligencia Artificial (IA). La RA es una amplificación del mundo cotidiano mediante la potencia de diversos tipos de TD asistidos por algoritmos muy sofisticados de IA. Aquí nos aproximamos, de nuevo, a los metaversos: universos más allá de éste, pero en relación íntima.

La RA ha estado disponible en el mercado desde hace algunos años. Se popularizó en gran parte del mundo hacia mediados del año 2016 cuando se lanzó el juego digital Pokémon $G O^{36}$ de la compañía Niantic $^{37}$. En la actualidad las investigaciones y aplicaciones son variadas y prometen tener un despliegue fuerte en los próximos años a partir de usos diversos en la vida cotidiana e incluso en la pesquisa en distintos campos, como la educación, la medicina, el turismo y el diseño, entre muchos otros $^{38}$.

En esencia la RA está conformada por un conjunto de TD que permiten la superposición, en tiempo real, sincrónico, de distintos tipos de información, imágenes y marcadores, generados virtualmente, pero que tienen relación con el mundo real físico. Se mezcla la realidad factual con la virtualidad, por ello se acuña el concepto de RA. Hasta ahora el mayor despliegue se ha generado a partir de los smartphones o celulares de alta gama, aunque para el futuro cercano muchas compañías anuncian dispositivos diferentes, como gafas y lentes de contacto. La conectividad permanente es indispensable para que la RA funcione, lo cual se conjuga con la necesidad de una cámara de captura de imágenes de un entorno real, una pantalla que proyecte las imágenes reales mezcladas con virtuales, sistemas de procesamiento de datos en tiempo real y mecanismos de interactividad de respuesta rápida y amigables ${ }^{39}$.

\footnotetext{
${ }^{34}$ Noyola, 2011.

${ }^{35}$ Colectivo Miradas Críticas del Territorio desde el Feminismo, 2017.

${ }^{36}$ Algunas de las características centrales pueden consultarse en: Rodríguez, 2017.

${ }^{37}$ Niantic, $2020<$ https://www.nianticlabs.com/>.

${ }^{38}$ Sobre la diversidad de aplicaciones de la RA recomiendo consultar: Fundación Telefónica, 2011; Cabero, De La Horra y Sánchez, 2018; Mullen, 2012; Miglino, Nigrelli y Sica (ed.), 2013; Cisneros, 2013; Grevtsova y Sibina, 2018; Peddie, 2017; Jung y Dieck, 2017; Bimber y Raskar, 2005.

${ }^{39}$ Sugiero visualizar: Computer Hoy, 2016 <https://www.youtube.com/watch?v=NfQPkY0cp2I>.
} 
Muchas compañías hegemónicas en el mundo están apostando por la RA y gastando cifras astronómicas de dinero en investigación y desarrollo de distintas aplicaciones, en especial para el consumismo digital y el entretenimiento. ¿Acaso una forma de lobotomía electrónica? Entre ellas Facebook ha mostrado adelantos significativos en el uso de RA para teléfonos celulares, a partir de aplicaciones de efectos básicos para los rostros de las personas - caras de personas con orejas y nariz de perro, por ejemplo-, localización precisa conjugada con mapeo a escala micro -para objetos pequeños-, captura e interacción espacial usando escenas en $3 \mathrm{D}$ con alta precisión en entorno locales, además del reconocimiento y la catalogación de objetos físicos en tiempo real, entre muchas otras opciones ${ }^{40}$.

Los orígenes de la RA hay que ubicarlos en el contexto de la convergencia tecnológica surgida, en esencia, desde mediados del siglo XX, a partir de la agregación de diversos avances que han permitido su materialización en la actualidad. De manera sintética, los inicios de la RA se sitúan en los videojuegos -que obviamente se soportan en otras técnicas precedentes- y los satélites de telecomunicaciones, transitando paulatinamente hasta los sistemas de geoposicionamiento global y el modelamiento cartográfico digital del planeta Tierra ${ }^{41}$ :

-Inteligencia Artificial (IA), 1956.

-Geoprocesamiento y geoposicionamiento, 1962.

-Sistemas de Información Geográfica (SIG), 1962.

-Computer Assistant Design (CAD), 1966.

-Realidad Virtual (RV), 1978.

-Digital Earth, ¿1995?

-Realidad Aumentada (RA), 2000.

-Google Earth, 2004.

-World Wind, 2006.

-Pokémon Go, 2016.

Los anteriores hitos tecnológicos son apenas algunos de los más relevantes para la emergencia de la RA, por lo cual deben asumirse como parte de procesos más amplios y complejos. Entre los precedentes más potentes para la expansión y la socialización de la RA se encuentran los mundos virtuales masivos en línea, más cercanos a la $\mathrm{RV}^{42}$, dentro de los cuales vale la pena destacar:

-Active Worlds, $1995^{43}$.

-Second Life, $2003^{44}$.

-World of Warcraft, $2004^{45}$.

Los tres hitos anteriores son apenas una muestra muy ínfima, aunque representativa, de los videojuegos en línea que están sentando las bases para que la RA se amplifique de manera potente y medie la relación de las sociedades con los espacios públicos y los privados, tanto factuales como virtuales. ¿Cómo categorizar y comprender un espacio público, por ejemplo, una plaza, un parque o

\footnotetext{
${ }^{40}$ Consúltese: Cnet, 2017 <https://www.youtube.com/watch?v=3pwNjs7rh1s>, <https://www.cnet.com/es/>.

${ }^{41}$ Listado de elaboración propia a partir de diversas fuentes.

${ }^{42}$ Al respecto sugiero consúltese: Rojas y Chaparro, $2012<$ http://www.ub.es/geocrit/aracne/aracne-166.htm>.

${ }^{43}$ Active Worlds, $2021<$ https://www.activeworlds.com/>.

${ }^{44}$ Second Life, $2021<$ https://secondlife.com/>.

${ }^{45}$ World of Warcraft, $2021<$ https://www.blizzard.com/es-es/>.
} 
¿Telarañas digitales e hiperrealidad? Cavilaciones sobre ciberespacios, proto-cíborgs y...

la calle, cuando puede ser utilizado por una compañía privada para desplegar una RA usando la potencia de Internet y las constelaciones de satélites de geo-posicionamiento en tiempo real? ¿Un proto-cíborg que utilice RA en un espacio público está contribuyendo, sin saberlo, a privatizarlo?

\section{Espacios públicos hiper-privatizados}

Cavilemos respecto a la siguiente situación real ocurrida durante varios días del segundo semestre del año 2016: grupos de jóvenes recorren de manera frenética el campus de la Universidad Nacional de Colombia (UNC) en Bogotá, buscando localizar Pokémones con sus teléfonos celulares o tabletas; parte de los jóvenes son estudiantes, pero muchos están ajenos a la academia, es decir no son universitarios y no se encuentran inscritos en ninguna clase. Están allí únicamente para seguir el juego de RA. Incluso algunos padres alentaban y acompañaban a sus hijos a jugar ${ }^{46}$.

En esta situación el espacio público corresponde al campus de la UNC, pero podría ser otro lugar de casi cualquier porción del planeta que cumpla ciertas condiciones de infraestructura de telecomunicaciones básica que soporte la conexión de un smart phone: un parque, una calle, una reserva natural, un museo, un jardín botánico. Los jóvenes que están enganchados al juego de RA, universitarios o no, usan el espacio público para su diversión. Una empresa privada, Niantic Inc., cuyo cuartel general queda ubicado en San Francisco, California, ha decidido de alguna manera, posiblemente mediante las disposiciones tomadas por un algoritmo muy complejo, seguramente más próximo a una IA, que allí, en el lugar y tiempo precisos y sincrónicos, los Pokémones -monstruos o bestias virtuales- cobran vida en su entorno digital y pueden ser observados y perseguidos en las instalaciones de la UNC, es decir en el mundo real-factual.

A partir de esta seguidilla de situaciones y acciones concatenadas pueden surgir muchas preguntas profundas:

-¿Por qué una empresa privada transnacional decide lanzar Pokémones, es decir criaturas virtuales, en el campus de una universidad pública?

- ¿Al usar un espacio público con fines lucrativos la compañía Niantic está privatizando de manera factual ese lugar? ¿Es correcto lucrarse de manera privada usando espacios públicos destinados a la educación?

-¿Una IA decidió escoger ese lugar para lanzar los monstruos virtuales? ¿Por qué allí y no en otro sitio? ¿O esto lo decidió un cuasi adolescente desde uno de los centros de comando del juego a miles de kilómetros de distancia? ¿Quién o qué decidió lanzar en la UNC los Pokémones?

-¿Existe algún tipo de legislación que controle el uso privado de los espacios públicos por parte de compañías privadas transnacionales? ¿Estas compañías se aprovechan, precisamente, de este vacío jurídico? ¿A qué entidad piden permiso estas empresas? ¿No solicitan permisos a nadie?

¿Los sistemas que definen la legislación sobre espacios públicos son conscientes de las implicaciones de estos fenómenos? ¿La alta tecnología siempre irá por delante de las personas lentas y retrógradas que definen las leyes y las normas de lo público?

\footnotetext{
${ }^{46}$ Sobre lo ocurrido en la Universidad Nacional de Colombia recomiendo visualizar el siguiente vídeo, publicado el 13 de julio de 2016: 〈https://www.youtube.com/watch?v=oOWXFKcGR0E>.
} 
-¿En qué se invierte el dinero obtenido como ganancias a causa del pago de los jóvenes por jugar una RA dentro de un espacio público universitario?

No pretendo responder al milímetro estos interrogantes pues para ello debería tener acceso a información privilegiada muy difícil de obtener. No obstante, sí es posible señalar que aquí surge un dilema geográfico muy sugestivo respecto a la privatización, mediante las TD y la RA, de espacios públicos, sea en Bogotá, o en cualquier otra ciudad del mundo, en disímiles territorios públicos. Pese a las limitaciones, puedo señalar que la lógica invasiva de las TD, vinculada a su perspectiva multiescalar, afecta de manera concreta a lo local, al lugar, al sitio puntual, mediante el despliegue de telarañas digitales, infraestructuras muy potentes y refinadas, soportadas en tecnologías de punta, que cada vez más se relacionan con segmentos de grupos humanos que no son conscientes por completo de la complejidad involucrada en sus actos.

Ya se ha escrito relativamente bastante sobre la privatización del espacio público desde distintos ángulos ${ }^{47}$. Aquí pretendo aportar a esta discusión desde la reflexión en torno a cómo la RA, conjuntos de tecnologías potentes apenas desplegadas de forma embrionaria, ya está afectando los espacios públicos sin que las entidades estatales, los académicos y los científicos, como arquitectos, politólogos y geógrafos, presten atención a este fenómeno de relevancia y trascendencia para la relación de las sociedades con sus espacios públicos.

Hasta este momento queda claro, aunque hay que reconocer que se debe investigar y reflexionar más sobre este fenómeno, que la RA está privatizando de manera profunda el espacio público mediante el usufructuo del espectro electromagnético. Técnica y factualmente los Estados, los gobiernos, están privatizando el espectro electromagnético, es decir la naturaleza. Una vez más la naturaleza, en este caso física, es apropiada de manera privada. ¿Los ciudadanos tenemos derecho a saber qué se hace con el espectro electromagnético? ¿Debería ser un bien común el espectro electromagnético?

${ }^{47} \mathrm{Al}$ respecto recomiendo consultar: Canclini (Coord.), 2004. 
¿Telarañas digitales e hiperrealidad? Cavilaciones sobre ciberespacios, proto-cíborgs y...

Figura 1. Pikachu de Pokémon GO transmutado en el flautista de Hamelín

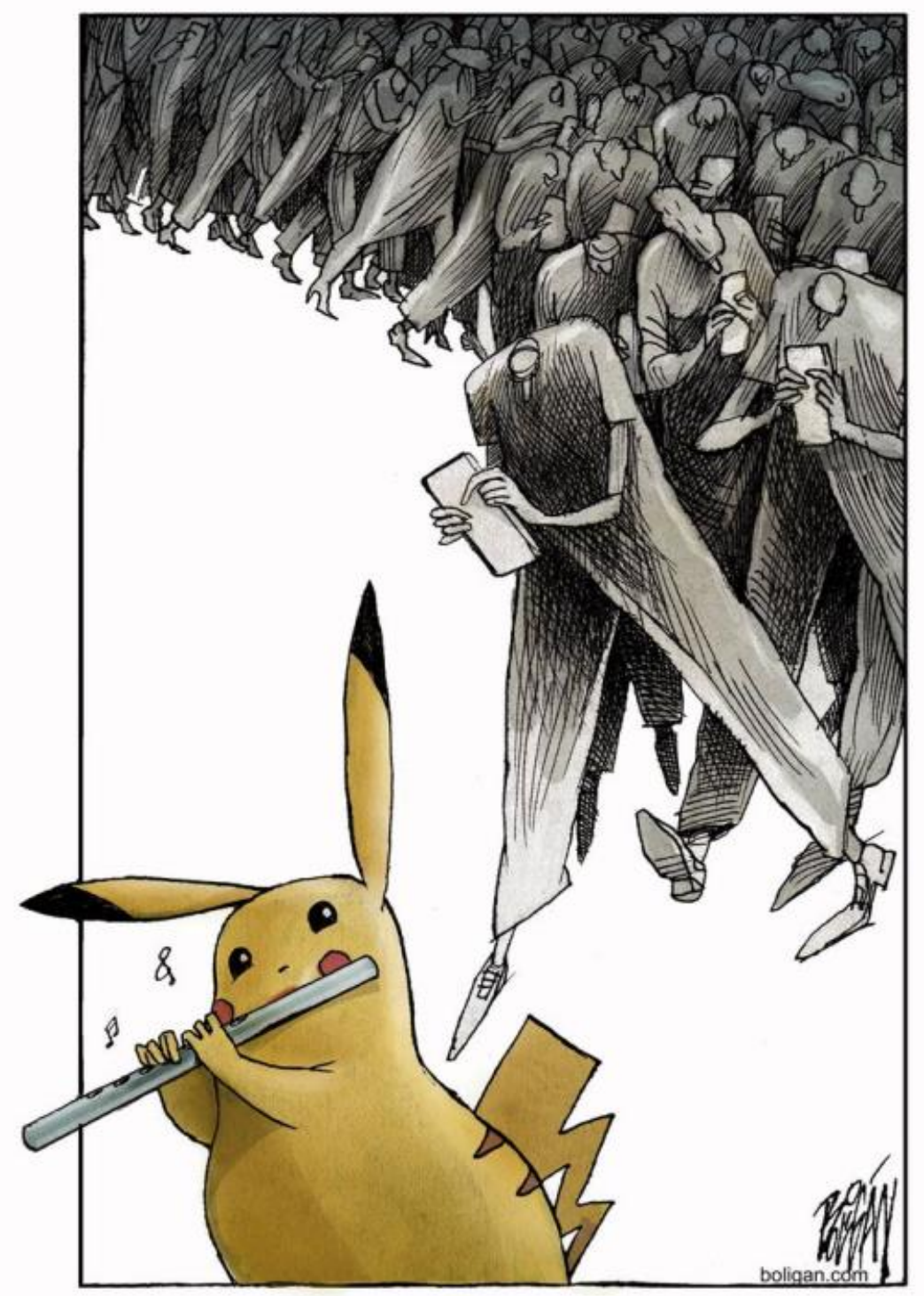

Fuente: Boligan. Bajo licencia Creative Commons.

En la figura se destacan dos elementos centrales: un Pokemón Pikachu en color amarillo, sosteniendo una flauta, y una turba de gente gris con cabezas diminutas o casi inexistentes que mantienen un aparato en la mano, un smart phone, y que persiguen a la criatura virtual. Esta caricatura refleja muy bien la relación espacial establecida a partir de la situación real en la UNC. Así actúa el ciberespacio a partir de los avances de la RA. ¿Qué posibilidades futuras tendrán este tipo de avances e innovaciones tecnológicas? 


\section{¿Realidad Aumentada para el conocimiento o para el hiperconsumo? Pistas desde el cine de ciencia ficción de Keiichi Matsuda}

Todo fenómeno tecnológico tiene múltiples aristas de análisis y discusión si lo abordamos desde la complejidad. La RA no es la excepción. Podría contribuir a que muchos campos del conocimiento, en especial los asociados al territorio y al paisaje, puedan explorar facetas inéditas vinculadas a la relación simultánea entre información hipermedial -el ciberespacio- cruzada en tiempo real con datos del mundo factual -espacio-. Desde otro ángulo la RA también podría ayudar a consolidar un mundo en el que la mayoría de la gente se vincule, aún más, al hiperconsumo de información ${ }^{48}$. en muchos casos poco relevante para su vida y su existencia. La penetración masiva de la RA en la sociedad podría favorecer el control social y territorial, terreno ya abonado de manera fuerte por Internet, los computadores y la telefonía celular.

Con la intención de reflexionar sobre las posibles implicaciones de la RA en los espacios públicos, y por su apuesta discursiva y tecnológica, he decidido en este segmento partir del análisis crítico de dos piezas de cine de documental de ciencia ficción creadas por Keiichi Matsuda ${ }^{49}$. Desde mi perspectiva la primera de ellas es de corte utópico y la segunda de corte distópico ${ }^{50}$.

La pieza uno se titula Veuve Clicquot ${ }^{51}$. Aborda varios elementos reales sobre la creación de diversos tipos de vino francés, por lo que podría considerarse como promocional. El filme propone una inmersión en la atmósfera de las bodegas francesas de almacenamiento de las botellas, para poco a poco dar paso a imágenes que proponen aumentar la realidad espacial fílmica, de corte documental, añadiendo información específica sobre el contexto histórico y diacrónico de la creación del vino. El director añade elementos de RA muy potentes, tipo fantaciencia, con compendios de corte espacial a distintas escalas, a partir de modelos de haciendas dedicadas al vino, datos sobre procesos micro de cambio de inclinación de las botellas, hasta el mapeo en el suelo de una bodega de distintas zonas productoras de vino que permiten visualizar, de manera clara y didáctica, las denominaciones de origen y sus tipos de vino asociados, en un ambiente completamente territorial, georeferenciado, que incluye asentamientos humanos, vías y coberturas del suelo (figura 2). El audiovisual es una invitación sintética para apreciar la complejidad espaciotemporal inmersa en la elaboración del vino. También permite vislumbrar las potencialidades de la RA para aplicaciones de corte geográfico, histórico, ingenieril, pasando por la agronomía y la química. Evidentemente es una apuesta que podría definir con potencia el marketing territorial.

\footnotetext{
${ }^{48}$ Lipovetsky, 2010.

${ }^{49}$ En cuanto al análisis crítico del discurso audiovisual sugiero consultar: Buxó y De Miguel (Eds), 1999.

50 Sobre la relación de la geografía y la ciencia ficción desde las utopías y las distopías, véase: Chaparro, Velandia y Giraldo, 2016 <http://www.ub.edu/geocrit/xiv-coloquio/ChaparroVelandiaGiraldo.pdf>; Chaparro, Ávila y Giraldo, 2018 <http://www.ub.edu/geocrit/Sociedad-postcapitalista/ChaparroAvila.pdf>.

${ }^{51}$ Matsuda, 2013, 5 min. <https://vimeo.com/chocobaby>.
} 
Figura 2. Fotograma de Veuve Clicquot

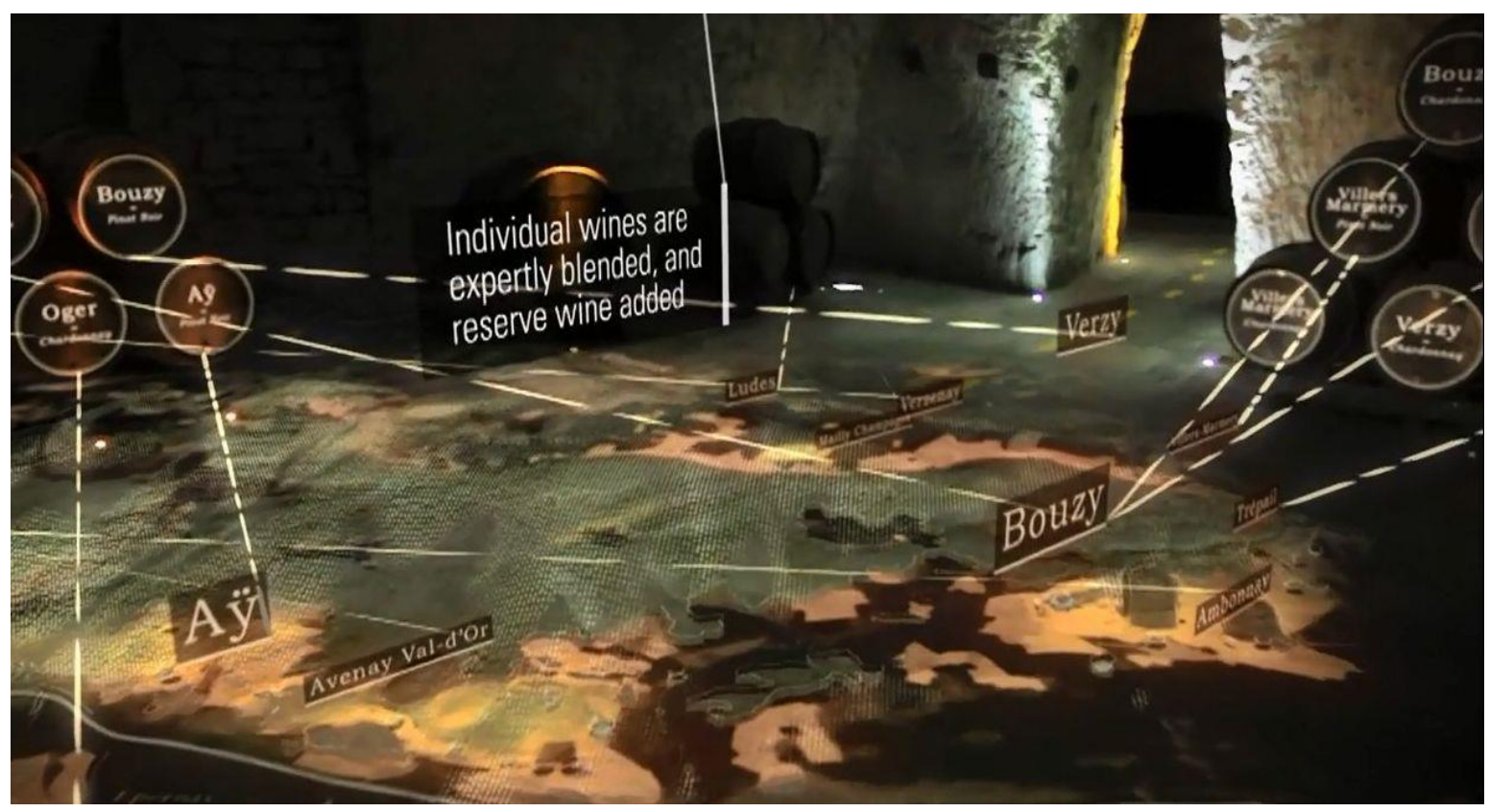

Fuente: Matsuda, $2013<$ https://vimeo.com/chocobaby>.

Al reflexionar sobre la anterior pieza cinematográfica no es fácil contenerse respecto a las cavilaciones asociadas a las propuestas imaginativas inmersas en las posibles aplicaciones de la RA en distintos campos de interés por el espacio público, ya sea desde las artes, las humanidades, como las ciencias naturales y agrarias.

Desde la arquitectura sería factible imaginar un recorrido por el espacio público. Podrían ser las calles de un centro histórico, poniendo énfasis en las fachadas de edificios de interés patrimonial, superponiendo al recorrido información valiosa en tiempo real sobre los diseñadores, los ejecutores, el contexto histórico, las restauraciones, los materiales utilizados, hasta las normas que catalizan su estado actual de conservación o degradación. En la misma situación un geógrafo podría presentar de manera conjunta, a partir de un recorrido de campo, aspectos clave del devenir territorial y su transformación diacrónica, clasificaciones del paisaje utilizando diversas apuestas teóricometodológicas, información sobre elitización de la zona, valor del suelo, uso comercial de la calle, normas de recalificación, planes de ordenamiento territorial y vínculos multiescalares con distintos vectores de la globalización. Incluso alguien desde la biología podría desplegar imágenes sobre la vegetación existente en un parque o en los andenes del mismo centro histórico hipotético, con información detallada respecto a los tipos de árboles, a sus orígenes, a la forma en que fueron introducidos o conservados, su edad, hasta datos dendrocronológicos que permitan ligar su información a las reconstrucciones climáticas que se están realizando en la actualidad. Cada campo del conocimiento interesado en un centro histórico podría utilizar la RA de formas muy sugestivas. 
La pieza dos se denomina Hiper-reality ${ }^{52}$. Consta de un frenesí de imágenes en distintos contextos urbanos populares de la ciudad de Medellín, que van desde el interior de un bus de servicio público hasta un supermercado de cadena, pasando por distintas posibilidades que ofrece la calle (figura 3). En todos los paisajes fílmicos, de corte documental mezclado con aportes distópicos de ficción científica, la sobresaturación de información genera una especie de indigestión cerebral, a tal punto que queda clara la tendencia excesivamente manipuladora, tanto del espacio personal, es decir el cuerpo, como del territorio por el que se transita, se vive y se respira. Aquí el director logra simular una inmersión total en la RA desde la arista de la vida cotidiana globalizada asociada al hiperconsumo y al trabajo paupérrimo. La dependencia tecnológica es tal, que la RA favorece la labor de una mujer a la que no le agrada que deba hacer mercados para sobrevivir, siendo en realidad profesora, denotando la angustia existencial de identidad vinculada a la precarización laboral y la inseguridad informática y callejera.

Figura 3. Fotograma de Hiper-reallity

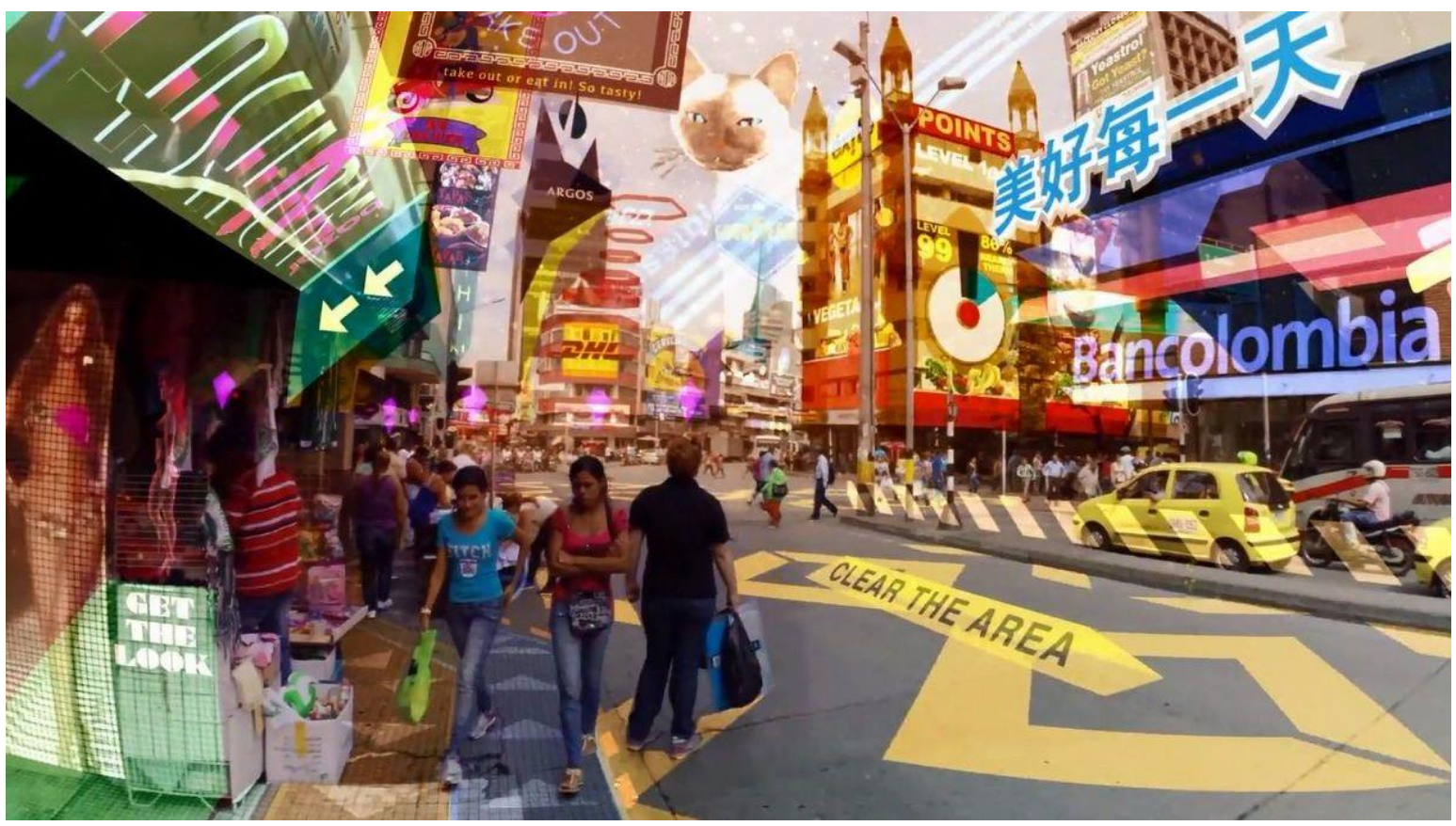

Fuente: Matsuda, $2016<$ https://vimeo.com/chocobaby>.

En esta pieza audiovisual también la calle y el espacio público son protagonistas. Cualquier pared, cualquier andén, puede sostener una seguidilla agobiante de imágenes publicitarias que sobresaturan el paisaje urbano. Las personas son expuestas a gran cantidad de información, en especial ligada al hiperconsumo, de tal manera que a la realidad se le añaden capas distintas de datos que, como telarañas digitales, atrapan al ciudadano, es decir al proto-cíborg.

En esta situación también podrían participar, desde el análisis y la discusión, distintos campos del conocimiento interesados en la calle y el espacio público. Desde la sicología se podría analizar el

\footnotetext{
${ }^{52}$ Matsuda, 2016, 6 min. <https://vimeo.com/chocobaby>.
} 
¿Telarañas digitales e hiperrealidad? Cavilaciones sobre ciberespacios, proto-cíborgs y...

papel de la RA en el comportamiento manipulado en los lugares recorridos, al igual que la angustia de ser contratado por un sistema autónomo, que podría ser una IA. A partir la antropología tal vez se podría analizar el papel de las prácticas híbridas de los humanos-máquina y de las nuevas pautas culturales mediadas por la RA. La geografía podría interesarse por la multiescalaridad inmersa en los distintos flujos de información que median la relación de las personas con el espacio urbano, la calle y lo público, al igual que en las pautas de segregación espacial asociadas al acceso y uso diferencial de las tecnologías digitales, con énfasis en la RA. Muchas serían las posibilidades, desde ángulos científicos variados, para abordar la complejidad de los escenarios urbanos inmersos en esta apuesta estética de anticipación frente a la RA.

La RA posee toda la potencialidad para generar cambios sustanciales en innumerables campos del conocimiento, incluyendo la biotecnología, la nanotecnología y las ciencias aeroespaciales. También podría sentar las bases de sociedades controladas en exceso y asfixiadas a causa de las órdenes provenientes de algoritmos muy refinados y de sistemas de IA desbordados. Es probable que surjan visiones resistentes y distanciadas en cuanto al uso de la RA, tanto para las ciencias como para las sociedades y los territorios.

Durante los últimos años, en especial respecto a la última década, algunos largometrajes de fantaciencia han tratado el tema de la RA. El análisis de sus discursos permitiría profundizar aún más en la prospectiva asociada a los efectos potenciales de la RA en la vida humana y en el espacio; no obstante, un abordaje detallado rebasaría el contexto de este escrito. Dentro de las obras cinematográficas que considero valdría la pena visualizar para vislumbrar los posibles efectos de la RA destaco las siguientes:

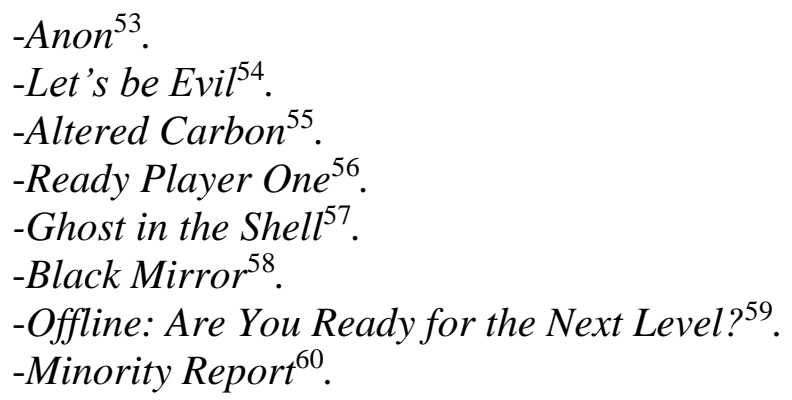

En los filmes anteriores el espacio es altamente invadido por lo privado. Lo cual incluye tanto a los espacios íntimos como a los espacios públicos. ¿Será posible que las ideas de control total, por parte de líneas políticas y religiosas centenarias -y en algunos casos milenarias-, se materializarán a partir de la extensión y difusión amplia de la RA en el mundo?

\footnotetext{
${ }^{53}$ Niccol, 2018, 1h 40min.

${ }^{54}$ Owen, 2016, 1h 22min.

${ }^{55}$ Kalogridis (Cread.), 2018, 10 cap.

${ }^{56}$ Spielberg, 2018, 2h 20min.

${ }^{57}$ Sanders, 2017, 1h 47min.

${ }^{58}$ Brooker (Cread.), 2011-2018, 19 episodios.

${ }^{59}$ Schnell (Dir.), 2016, $1 \mathrm{~h} 31 \mathrm{~min}$.

${ }^{60}$ Spielberg, 2002, 2h 25min.
} 


\section{La realidad aumentada y el desierto de lo real: ¿hacia la hiperrealidad?}

La RA conjuga tecnologías digitales de vanguardia coligadas a avances sustanciales en varios campos, como las ingenierías, las matemáticas, la física y los sistemas computacionales. Aunque el ciberespacio se ha extendido mucho, tanto en términos sociales como espaciales, aún como fenómeno se encuentra en sus primeras fases. No obstante, los espacios electrónicos y digitales ya ofrecen los elementos necesarios para la cimentación de la RA, situación favorecida por el nivel de artificialidad al que hemos llegado como humanos proto-cíborgs.

Los usos e implicaciones sociales derivadas de la RA hasta ahora empiezan a vislumbrarse, de tal manera que su potencialidad es muy sugestiva. Podría contribuir a impulsar avances en muchos campos del conocimiento, incluyendo las artes y las humanidades. Pero la RA también conseguiría erigirse como un macro fenómeno que propicie el control humano y espacial con niveles bastante refinados y potentes. Como ocurre con cualquier avance de punta en tecnologías digitales, las implicaciones se manifestarán con el tiempo, y en especial se asociarán con las formas de difusión y apropiación social, por lo cual no conviene partir de premisas ligadas a determinismos tecnológicos. Pese a ello, el rumbo que están tomando estas tecnologías es más bien oscuro, pues va muy de la mano del control, la vigilancia, la manipulación y el hiperconsumo. La RA podría contribuir a una mayor alienación y esnobismo social. Por consiguiente, también sería territorial.

La RA genera retos sustanciales al momento de pensar los espacios públicos. Es evidente que el manejo del espectro electromagnético a partir de tecnologías digitales de última generación, muchas derivadas de avances militares y de inteligencia, en conjunción con la expansión de Internet, derivan en una situación poco deseable: los espacios públicos están altamente privatizados mediante la RA. Y en gran medida esa privatización se define por los vectores del hiperconsumo, que infla los bolsillos de grandes compañías transnacionales dedicadas a traficar con los bites, con ceros y unos $(0,1)$, con información digital, lo cual está derivando en nuevos tipos de drogas electrónicas, que se consumen con vehemencia y generan bastante adicción, hasta el punto de enfermar el cuerpo y la mente. La RA podría derivar en nuevas adicciones.

Otro gran reto asociado a la irrupción de la RA consiste en el remplazamiento de la complejidad de la realidad por la simplificación de la virtualidad, asunto que es muy delicado. Si la realidad factual ya es inmensamente compleja, añadirle capas de virtualidad de manera sincrónica puede generar indigestión de información, y también contribuir a la simplificación de los paisajes, los territorios y los espacios, mediante información poco o nada relevante, dependiendo del caso concreto. La simplificación a partir de la desviación de la atención hacia lo importante. La RA como mediadora de la representación de la realidad es sumamente peligrosa. Toda esta situación en conjunto nos lleva a discutir de nuevo, ahora de manera amplificada, el asunto del simulacro, tema no finiquitado y que ofrece perspectivas futuras de investigación y reflexión bastante prometedoras.

Aunque hace varias décadas se realizaron apuestas teóricas, conceptuales y epistemológicas potentes frente a las situaciones emergentes, en gran medida de anticipación frente a las consecuencias de las telecomunicaciones, es muy posible que tan solo hasta ahora realmente dimensionemos algunos de 
¿Telarañas digitales e hiperrealidad? Cavilaciones sobre ciberespacios, proto-cíborgs y...

sus efectos y visualicemos la profundidad con la que el simulacro, concepto trabajado a profundidad por Jean Baudrillard, está afectando nuestra realidad, la cotidianidad y los espacios públicos ${ }^{61}$ :

Si ha podido parecernos la más bella alegoría de la simulación aquella fábula de Borges en que los cartógrafos del Imperio trazan un mapa tan detallado que llega a cubrir con toda exactitud el territorio (aunque el ocaso del Imperio contempla el paulatino desgarro de este mapa que acaba convertido en una ruina despedazada cuyos girones se esparcen por los desiertos -belleza metafísica la de esta abstracción arruinada, donde fe del orgullo característico del Imperio y a la vez pudriéndose como una carroña, regresando al polvo de la tierra, pues no es raro que las imitaciones lleguen con el tiempo a confundirse con el original) pero ésta es una fábula caduca para nosotros y no guarda más que el encanto discreto de los simulacros de segundo orden.

Hoy en día, la abstracción ya no es la del mapa, la del doble, la del espejo o la del concepto. La simulación no corresponde a un territorio, a una referencia, a una sustancia, sino que es la generación por los modelos de algo real sin origen ni realidad: lo hiperreal. El territorio ya no precede al mapa ni le sobrevive. En adelante será el mapa el que preceda al territorio -precesión de los simulacros- y el que lo engendre, y si fuera preciso retomar la fábula, hoy serían los girones del territorio los que se pudrirían lentamente sobre la superficie del mapa, los que todavía subsisten esparcidos por unos desiertos que ya nos son los del Imperio, sino nuestro desierto. El propio desierto de lo real.

De hecho, incluso invertida, la metáfora es inutilizable. Lo único que quizá subsiste es el concepto de Imperio, pues los actuales simulacros, con el mismo imperialismo de aquellos cartógrafos, intentan hacer coincidir lo real, todo lo real, con sus modelos de simulación. [...].

La hiperrealidad, la RA, nos invita a cavilar respecto a si el territorio y lo humano, el todo, el Universo, funciona a modo de hologramas incrustados en telarañas digitales... Cuerdas y membranas de espacio-tiempo...

\section{Recursos bibliográficos, digitales y fílmicos}

ACTIVE WOLDS. Newburyport, Massachussets: Active Worlds Inc, 2021 $<$ https://www.activeworlds.com/>.

AGILAR, Teresa. Ontología Cyborg: El cuerpo en la nueva sociedad tecnológica. Barcelona: Gedisa, 2009, 160 p.

ARISO, José (Editor). Augmented Reality: Reflections on Its Contribution to Knowledge Formation. Volumen 11. Berlin Studies in Knowledge Research. Berlín: De Gruyter, 2017, 329 p.

ARTEAGA, Nelson. Política de la verticalidad: drones, territorio y población en América Latina. Región y Sociedad. Hermosillo, México: El Colegio de Sonora, enero-abril, 2016, vol. XXVIII, $\mathrm{n}^{\circ}$ 65, p. 263-292 <http://www.redalyc.org/pdf/102/10243267008.pdf>.

ARNALDI, Bruno; GUITTON, Pascal; MOREAU, Guillaume (Editors). Virtual Reality and Augmented Reality: Myths and Realities. New Jersey: John Wiley \& Sons, 2018, 370 p.

${ }^{61}$ Baudrillard, 1978, p. 9-10. 
ASSANGE, Julian. Cypherpunks: Freedom and the Future of the Internet. New York, London: OR Books, 2012, 186 p.

AUKSTAKALNIS, Steve. Practical Augmented Reality: A Guide to the Technologies, Applications, and Human Factors for AR and VR. New York: Addison-Wesley, 2016, 450 p.

BATTY, Michael. Virtual geography. Futures. Amsterdam: Elsevier, 1997, 29 (4-5), p. 337-352.

BARBIC, Jernej; D'CRUZ, Mirabelle; LATOSCHIK, Marc; SLATER Mel; BOURDOT, Patrick (Editors). Virtual Reality and Augmented Reality: 14th EuroVR International Conference, EuroVR 2017, Laval, France, December 12-14, 2017, Proceedings. New York: Springer, 2017, 193 p.

BAUDRILLARD, Jean. Cultura y simulacro. Barcelona: Kairós, 1978, 196 p.

BAUMAN, Zygmunt. Vida de consumo. México D.F.: Fondo de Cultura Económica, 2009, 205 p.

BERGEN. Peter; TIEDEMANN, Katherine. Whashington phatom war. The effect of the U.S. Drone program in Pakistan. Foreign Affairs. Council on Foreign Relations, julio-agosto, 2011. Vol. $90 \mathrm{~N}^{\circ}$ 4, pp 12-18 <http://www.jstor.org/stable/23039602>.

BIMBER, Oliver; RASKAR, Ramesh. Spatial Augmented Reality: Merging Real and Virtual Worlds. Boca Raton, FL: CRC Press, Taylos \& Francis, 2005, 392 p.

BROOKER, Charlie (Creador). Black Mirror. United Kingdom: Zeppotron, Channel 4 Television Corporation, Gran Babieka, 2011-2018, 4 temporadas, 19 episodios, 1 filme interactivo (Bandersnatch).

BUXÓ, M.a. Jesús; DE MIGUEL, Jesús (Eds.). De la investigación audiovidual: fotografía, cine, vídeo, televisión. Barcelona: Proyecto A Ediciones, 1999, 165 p.

CABERO, Julio; DE LA HORRA, Ibán; SÁNCHEZ, Javier (Coords). La realidad aumentada como herramienta educativa. Madrid: Paraninfo, 2018, 212 p.

CANCLINI, Néstor (Coordinador). Reabrir espacios públicos. Políticas culturales y ciudadanía. México D.F.: Universidad Autónoma Metropolitana, Plaza y Valdes, 2004, 397 p.

CARONÍA, Antonio. The Cyborg: A Treatise on the Artificial Man. Lüneburg, Germany: Meson Press, 2015, 172 p.

CHAPARRO, Jeffer. Un mundo digital. Territorio, segregación y control a inicios del siglo XXI. Bogotá: Universidad Nacional de Colombia, 2017, 357 p.

CHAPARRO, Jeffer; ÁVILA, Johanna; GIRALDO, Carlos. ¿Corregir el rumbo? Las distopías territoriales del cine de ciencia ficción y la necesaria reconfiguración del mundo capitalista. En: ZAAR, Miriam; CAPEL, Horacio (Coords. y Eds.). Las ciencias sociales y la edificación de una 
¿Telarañas digitales e hiperrealidad? Cavilaciones sobre ciberespacios, proto-cíborgs y...

sociedad post-capitalista. Barcelona: Universidad de Barcelona, Geocrítica, 2018. <http://www.ub.edu/geocrit/Sociedad-postcapitalista/ChaparroAvila.pdf>.

CHAPARRO, Jeffer; VELANDIA, Manuel; GIRALDO, Carlos. Teletrabajo, ciencia ficción y cibergeografía: contribuciones para comprender nuevas realidades laborales desde las utopías y las distopías. En: BENACH, Nuria; ZAAR, Miriam Hermi; VASCONCELOS P. JUNIOR, Magno (eds.). Actas del XIV Coloquio Internacional de Geocrítica: Las utopías y la construcción de la sociedad del futuro. Barcelona: Universidad de Barcelona, $2016<$ http://www.ub.edu/geocrit/xivcoloquio/ChaparroVelandiaGiraldo.pdf>.

CHAPARRO, Jeffer; CORONADO, Jhoan; GARCÍA, Miguel; RABIA, Achouak; ZÁRATE Andrés. El dron como herramienta tecnológica de control territorial. Ar@cne. Revista Electrónica de Recursos de Internet sobre Geografía y Ciencias Sociales. [En línea]. Barcelona: Universidad de

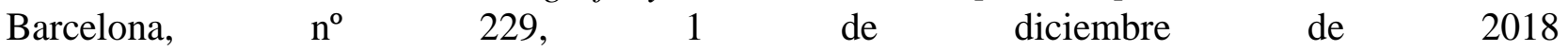
<https://revistes.ub.edu/index.php/aracne/article/view/28463/29134>.

CISNEROS, Andrés. Neuromarketing y neuroeconomía: Código emocional del consumidor. Bogotá: Ecoe Ediciones, 2013, 164 p.

CLARK, Andy. Natural-born Cyborgs: Minds, Technologies, and the Future of Human Intelligence. Oxford: Oxford University Press, 2004, 229 p.

CNET. Facebook quiere que disfrutes de la Realidad Aumentada desde tu móvil. San Francisco: Cnet en Español, $2017 \quad<$ https://www.youtube.com/watch?v=3pwNjs7rh1s>, $<$ https://www.cnet.com/es/>.

COLECTIVO MIRADAS CRÍTICAS DEL TERRITORIO DESDE EL FEMINISMO. Mapeando el cuerpo-territorio. Guía metodológica para mujeres que definen sus territorios. Quito: Clacso: 2017, 53 p.

COLEMAN, Gabriella. Hackers, activistas, espías y bromistas. Las mil caras de Anonymous. Barcelona: Arpa editores, 2016, 399 p.

COMPUTER HOY. ¿Qué es la Realidad Aumentada? Madrid: Computer Hoy, 2016 <https://www.youtube.com/watch?v=NfQPkY0cp2I>, <https://computerhoy.com/>.

DOMSCHEIT, Daniel. Dentro de WikiLeaks. Mi etapa en la web más peligrosa del mundo. Barcelona: Roca Editorial, 2011, 255 p.

EL PAÍS. El videojuego factura el doble que el cine y casi seis veces más que la música. El País Economía. Madrid: Ediciones El País, 2018, 5 de octubre <https://cincodias.elpais.com/cincodias/2018/10/05/companias/1538763165_030915.html>.

ETZIONI. Amitai. Drone attacks: the 'secret' matrix. The world Today. Royal institute of international affairs, julio 2010. Vol. 66, $\mathrm{n}^{\circ}$ 7, p. 11-14. <http://www.jstor.org/stable/41962544>. 
FISHER, Peter; UNWIN, David (Editors). Virtual Reality in Geography. London: Taylor \& Francis, 2002, 403 p.

FOELIX, Rainer. Biology of Spiders. Oxford: Oxford University Press, 2011, 419 p.

FUNDACIÓN TELEFÓNICA. Realidad Aumentada: una nueva lente para ver el mundo. Madrid: Fundación Telefónica, 2011, 97 p.

FURHT, Borko (Editor). Handbook of Augmented Reality. New York: Springer, 2011, 746 p.

GIBSON, William. Neuromancer. New York: Ace Books, 1984, 451 p.

GREBOWICZ, Margret; MERRICK, Helen. Beyond the Cyborg: Adventures with Donna Haraway. New York: Columbia University Press, 2013, 208 p.

GREENE, Brian. La realidad oculta: Universos paralelos y las profundas leyes del Cosmos. Barcelona: Crítica, 2011, 512 p.

GREGORY, Derek. From a view to a kill: Drones and late modern war. Theory, Culture \& Society. Enero 2012 , Vol. 28 , p. $188-215$ <http://journals.sagepub.com/doi/abs/10.1177/0263276411423027>.

GREGORY, Derek. The everywhere war. The Geographical Journal. 2011, vol. 177. <https://onlinelibrary.wiley.com/doi/full/10.1111/j.1475-4959.2011.00426.x>.

GREVTSOVA, Irina, SIBINA, Joan. Entre los espacios físicos y virtuales. Turismo cultural en el mundo digital. Valencia: Universidad de Valencia: 2018, 100 p.

HARARI, Yuval. Homo Deus. Breve historia del mañana. Barcelona: Debate, 2016, 490 p.

HARAWAY, Donna. Ciencia, cyborgs y mujeres: la reinvención de la naturaleza. Valencia: Universitat de València, 1995, 431 p.

HASHIM, Ahmed; GREGOIRE, Patte. What is that Buzz? The rise of Drone warfare. Counter Terrorist Trends and Analyses. International centre for political violence and terrorism research, Vol. 4, no 9, 2012, p. 8-13 <http://www.jstor.org/stable/26351086>.

HASIAN, Marouf. Drone Warfare and Lawfare in a Post-Heroic Age. Alabama: Universtiy of Alabama Press, 2016.

HERBERSTEIN, Marie. Spider Behaviour: Flexibility and Versatility. Cambirdge: Cambridge University Press, 2011, 416 p.

HERRERA, Juan. Breve historia del espionaje. Madrid: Noutilus, 2012, 301 p. 
¿Telarañas digitales e hiperrealidad? Cavilaciones sobre ciberespacios, proto-cíborgs y...

HERRERA, Gerardo. El Higgs, el Universo líquido y el Gran Colisionador de Hadrones. Ciudad de México: Fondo de Cultura Económica, 2014, 232 p.

HUANG, Weidong; ALEM, Leila; LIVINGSTON, Mark (Editors). Human Factors in Augmented Reality Environments. New York: Springer, 2012, 274 p.

JASSO, Karla. Arte, tecnología y feminismo: nuevas figuraciones simbólicas. Ciudad de México: Universidad Iberoamericana, 2008, 174 p.

JUNG, Timothy; DIECK, Claudia. Augmented Reality and Virtual Reality: Empowering Human, Place and Business. New York: Springer, 2017, 384 p.

KALOGRIDIS, Laeta (Creadora). Altered Carbon. USA: Mythology Entertainment, Skydance Television, 2018, 10 capítulos.

KISAK, Paul (Editor). The Multiverse: The Theories of Multiple Universes. Scotts Valley, California: Create Space Independent Publishing Platform, 2015, 200 p.

KREPS, Sarah; ZENKO, Micah. The Next Drone Wars: Preparing for Proliferation. Foreign Affairs. Council of foreign relations, marzo-abril 2014, vol. $93 \quad \mathrm{~N}^{\circ} 2$, p. $\quad 68-79$. <http://www.jstor.org/stable/24483585>.

LIPOVETSKY, Gilles. La felicidad paradójica: Ensayo sobre la sociedad de hiperconsumo. Barcelona: Anagrama, 2010, 416 p.

LIPOVETSKY, Gilles; SERROY, Gilles. La estetización del mundo. Vivir en la época del capitalismo artístico. Barcelona: Anagrama, 2014, 416 p.

LOMBARDI, Julian; LOMBARDI, Marilyn. Opening the Metaverse. In: SIMS, William. Online Worlds: Convergence of the Real and Virtual. Human-Computer Interaction Series. New York: Springer, 2010, p. 111-122, 318 p.

LÓPEZ, Liliana. Geografía y ciberespacio. En: Tratado de Geografía humana. Barcelona: Anthropos, 2006, p. 536-553.

LUCAS, George. THX 1138. Estados Unidos de América: American Zoetrope, 1971, 88 min.

LUJÁN, Enric. Drones. Sombras de la Guerra contra el terror. Barcelona: Virus, 2015, 175 p.

MARCUS, Anthony; AIYER, Ananthakrishnan; DOMBROWSKI, Kirk. Droning on: The Rise of the Machines. Dialectical Anthropology. Springer, junio 2012, vol. $36 \mathrm{~N}^{\circ}$ 1-2, p. 1-5 <http://www.jstor.org/stable/23339219>.

MATSUDA, Keiichi. Alchemy. New York: Vimeo, 2013, 4:58 min. $<$ https://vimeo.com/chocobaby>. 
MATSUDA, Keiichi. Hiper-reallity. 2016, 6:15 min. <https://vimeo.com/chocobaby>.

MIGLINO, Orazio, NIGRELLI, María, SICA, Luigia (Editores). Videojuegos de rol, simulaciones por ordenador, robots y realidad aumentada como nuevas tecnologías para el aprendizaje: guía para profesores, educadores y formadores. Castellón de la Plana, Comunidad Valenciana: Universidad Jaume I., Servicio de Comunicación y Publicaciones, 2013, 138 p.

MULLEN, Tony. Realidad Aumentada. Crea tus propias aplicaciones. Madrid: Anaya Multimedia, 2012, $319 \mathrm{p}$.

NATIONAL AERONAUTICS AND SPACE ADMINISTRATION (NASA). Washington: NASA, $2021<$ https://www.nasa.gov/>.

NEHRU, Viskas. Global Wireless Spiderweb. The Invisible Threat Posed by Wireless Radiation. Gurgaon, India: Partridge Publishing, 2016, 222 p.

NIANTIC. San Francisco: Niantic Inc., 2021 <https://www.nianticlabs.com/>.

NICCOL, Andrew. Anon. Germany, USA, Canada: K5 Film, 1h 40min.

NICCOL, Andrew. Good Kill. USA: Dune Films, 2014, 1h 42min.

NOYOLA, Gabriela. Geografías del cuerpo. Por una pedagogía de la experiencia. Tlalpan, México: Universidad Pedagógica Nacional, 2011, 173 p.

OWEN, Martin. Let's be Evil. United Kingdom: Posterity Pictures, 2016, 1h 22min.

PIRES, Hindenburgo. Ar@cne.Revista de recursos en Internet sobre Geografía y ciencias sociales. Geografia das Indústrias Globais de Vigilância em Massa: Limites à liberdade de expressão e organização na Internet. Barcelona: Universidad de Barcelona, $\mathrm{n}^{\circ}$ 183, 1 de abril de $2014<\mathrm{http}: / / \mathrm{www} . u b . e s /$ geocrit/aracne/aracne-183.htm>.

PIRES, Hindenburgo. Governança Global da Internet: A representação de topônimos de países no ciberespaço. Scripta Nova. Revista Electrónica de Geografía y Ciencias Sociales. Barcelona: Universidad de Barcelona, 1 de agosto de 2008, vol. XII, núm. 270 (151) <http://www.ub.es/geocrit/sn/sn-270/sn-270-151.htm>.

POLLACK, Norman. Capitalism, Hegemony and Violence in the age of Drones. Gewerbestrasse (Switzerland): Palgrave Macmillan, 2018, 483 p.

RODRÍGUEZ, Pablo. Lo + Visto 1: La realidad aumentada llega a las calles. El caso Pokémon Go. Madrid: Fundación Telefónica, 2017, 17 p.

ROJAS, Sebastián y CHAPARRO, Jeffer. Paisajes virtuales en los Massive Multiplayer Online Role Playing Games: una aproximación al caso de Runes of Magic. Ar@cne. Revista Electrónica de 
¿Telarañas digitales e hiperrealidad? Cavilaciones sobre ciberespacios, proto-cíborgs y...

Recursos en Internet sobre Geografía y Ciencias Sociales. Barcelona: Universidad de Barcelona, $\mathrm{n}^{\circ}$ 166, 1 de diciembre de 2012 <http://www.ub.es/geocrit/aracne/aracne-166.htm>.

RON, Rodrigo; ÁLVAREZ, Antón; NUÑEZ, Patricia. Los efectos del marketing digital en niños y jóvenes: Smartphones y tablets ¿enseñan o distraen? Madrid: Esic, 2013, 161 p.

PEDDIE, Jon. Augmented Reality: Where We Will All Live. New York: Springer, 2017, 323 p.

SANDERS, Rupert. Ghost in the Shell. USA, India, Hong Kong, China: Paramount Pictures, DreamWorks, Reliance Entertainment, Shanghai Film Group, Huahua Media, Arad Productions, Steven Paul Production, Weying Galaxy Entertainment, Amblin Partners, Seaside Entertainment, 2017, 1 h 47min.

SANTANA, Daniel. CHAPARRO, Jeffer. BONASTRA, Quim. CAPEL, Horacio. La revista Ar@cne en los años 2010-2013 y el espionaje en la red. Ar@cne. Revista electrónica de recursos en Internet sobre Geografía y Ciencias Sociales. Barcelona: Universidad de Barcelona, $\mathrm{n}^{\mathbf{0}}$ 179, 1 de marzo de 2014 <http://www.ub.edu/geocrit/aracne/aracne-179.htm>.

SANTOS, Milton. La naturaleza del espacio. Técnica y tiempo, razón y emoción. Barcelona: Ariel, 2000, 384 p.

SECOND LIFE. San Francisco: Linden Lab, $2021<$ https://secondlife.com/>.

SCHNELL, Florian (Director). Offline: Are You Ready for the Next Level? Germany: Rat Pack Filmproduktion, Südwestrundfunk, ARTE, Bayerischer Rundfunk, Karl Filmproduktion, Filmakademie Baden-Württemberg, Piranha Bytes, 2016, 1h 31min.

SHAW, Ian. Predator Empire: The Geopolitics of US Drone Warfare. Geopolitics. Taylor and $\begin{array}{llllll}\text { Francis, } & \text { junio } & 2013, & \text { vol } & 18, & \text { p. }\end{array}$ <https://www.tandfonline.com/doi/abs/10.1080/14650045.2012.749241>.

SINGER, Katie. The Electronic Silent Spring: Facing the Dangers and Creating Safe Limits. Great Barrington (MA): Steiner Books, 2014, 310 p.

SPIELBERG, Steven. Minority Report. USA: Twentieth Century Fox, Dream Works, Wagner Productions, Blue Tulip Productions; Ronald Shusett, Gary Goldman, Amblin Entertainment, Digital Image Associates, 2002, 2h 25min.

SPIELBERG, Steven. Ready Player One. USA: Amblin Entertainment, De Line Pictures, Dune Entertainment, Farah Films \& Management, Reliance Entertainment, Village Roadshow Pictures, Warner Bros, 2018, 2h 20min.

VIERA, Carmen; GONZAGA, Marcelo. Behaviour and Ecology of Spiders. Switzerland: Springer, 2017, 437 p.

WARK, McKenzie. Un manifiesto hacker. Barcelona: Alpha Decay, 2006, 204 p. 
WASSOM, Brian. Augmented Reality Law, Privacy, and Ethics: Law, Society, and Emerging AR Technologies. Amsterdam: Syngress, Elsevier, 2014, 360 p.

WORLD OF WARCRAFT. Irvine, California: Blizzard Entertainment, 2021 $<$ https://www.blizzard.com/es-es/>.

YANG, Zhiyong; GU, Wenjin; ZHANG, Jing; GUI, Lihua. Force Control Theory and Method of Human Load Carrying Exoskeleton Suit. New York: Springer, 2017, 218 p.

Ficha bibliográfica:

CHAPARRO MENDIVELSO, Jeffer. ¿Telarañas digitales e hiperrealidad? Cavilaciones sobre ciberespacios, proto-cíborgs y realidades aumentadas en espacios públicos. Ar@cne. Revista Electrónica de Recursos de Internet sobre Geografia y Ciencias Sociales. Barcelona: Universidad de Barcelona, I de agosto de 202I, vol. XXV, n 257. DOI: https://doi.org/I0.1344/ara2021.257.35695

\section{Menú Geo Crítica}

